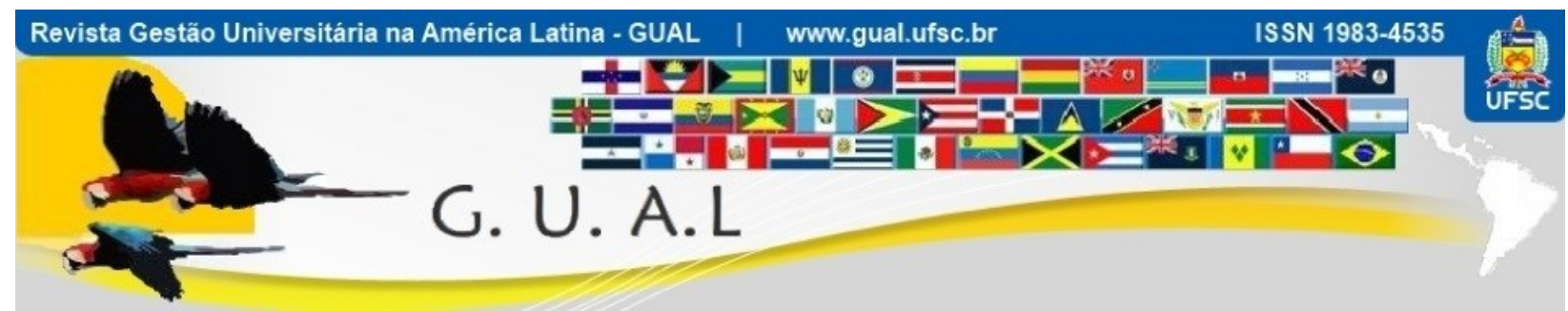

DOI: http://dx.doi.org/10.5007/1983-4535.2015v8n4p57

\title{
UNIVERSIDADE EMPREENDEDORA: A ÓTICA DOS EMPRESÁRIOS SOBRE O POSICIONAMENTO EMPREENDEDOR DA UNIVERSIDADE NA CONTRIBUIÇÃO PARA O DESENVOLVIMENTO REGIONAL
}

\section{ENTREPRENEURIAL UNIVERSITY: THE PERSPECTIVE OF ENTREPRENEURS ON THEPLACEMENT ENTREPRENEUR OF THE UNIVERSITY IN CONTRIBUTION TO REGIONAL DEVELOPMENT}

Cassiane Chais, Mestre Universidade de Passo Fundo - UPF cassichais@gmail.com

Claralucia Prates Machado, Doutoranda Universidade do Vale do Rio dos Sinos - UNISINOS clara@claramachado.com

Alexandra Mazzochi Scopel, Mestre Universidade de Caxias do Sul - UCS alemscopel@gmail.com

Cristina Bohrer, Mestranda Faculdade Meridional - IMED cris.bohrer@hotmail.com

Recebido em 05/dezembro/2014

Aprovado em 05/abril/2015

Sistema de Avaliação: Double Blind Review

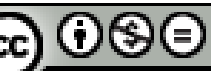

Esta obra está sob uma Licença Creative Commons Atribuição-Uso. 


\title{
RESUMO
}

A interação universidade-empresa está elencada como uma ferramenta propulsora do desenvolvimento tecnológico de um país. A empresa concentra suas atividades produtivas na economia e a universidade possui seu pilar na pesquisa e no conhecimento. Com estes importantes atores concentrando ações em conjunto, o desenvolvimento regional possui chances de atingir índices importantes de desenvolvimento para uma nação. Dessa forma, esta pesquisa buscou identificar a opinião de empresários sobre a importância do posicionamento empreendedor da universidade para o desenvolvimento de uma região. Para tanto, foi realizado um estudo multicaso com empresários, que possuem envolvimento com diferentes universidades. Foi empregada uma pesquisa exploratória de natureza qualitativa, cuja a técnica para a coleta de dados foi a aplicação de um questionário estruturado com perguntas abertas para três empresas indicadas pelos núcleos, em cada uma das três regiões de atendimento do PEPI: Região da Produção, Serra e Metropolitana do Estado do Rio Grande do Sul. Verificou-se que o empresariado anseia que as Universidades estejam presentes no contexto na qual estão inseridas e que a interação é dependente da visão e da necessidade de cada empresa.

Palavras-chave: Universidade Empreendedora. Interação Universidade-Empresa. Programa Extensão Produtiva e Inovação. Desenvolvimento regional.

\begin{abstract}
The university-industry interaction is alienated as a driving tool technologicaldevelopment of a country. The company focuses its production activities in the economy and the university has its pillar in research and knowledge. With these key players focusing actions together, regional development has chances of reaching important levels of development for a nation. Therefore, this study aimed to identify the opinion of entrepreneurs about the importance of entrepreneur positioning the university for the development of a region. Therefore, we performed a multi case study with entrepreneurs who have involvement with different universities. An exploratory qualitative research was used, whose technique for data collection was the application of a structured questionnaire with questions open for three companies nominated by cores, each of the three regions of the PEPI service:. Production Region, Sierra and Metropolitan of the Rio Grande do Sul State has been found that the business craves that universities are present in the context in they are engaged and that the interaction is dependent on the vision and the need each company.
\end{abstract}

Key words: Entrepreneurial University. Interaction University-Industry. Program Productive Innovation and Extension. Regional Development. 


\section{INTRODUÇÃO}

Em um ambiente econômico fundamentado no conhecimento e caracterizado pela existência de mercados dinâmicos e competitivos, emerge um elemento-chave para transpor os desafios, a busca constante pela inovação. Neste contexto, a interação universidadeempresa caracteriza a dinâmica da inovação, onde as relações se desenvolvem entre duas esferas institucionais, envolvendo os atores: universidade e empresa (ETZKOWITZ; LEYDESDORFF, 2000).

A interação solidifica o contexto onde universidade e empresa se unem a favor do desenvolvimento e assim, as universidades cooperam com o setor empresarial ocasionando benefícios para ambos (DAGNINO, 2003). A inovação almeja auxiliar no crescimento e desenvolvimento econômico onde as ondas de mudanças tecnológicas são, na maioria das vezes, descontínuas, destruindo as velhas indústrias e gerando novas. O fenômeno chamado destruição criadora (SCHUMPETER (1942).

Cabe à universidade a tarefa de criar fontes de novos conhecimentos e tecnologias, estabelecer relações com empresas, criar novas áreas de atuação e conduzir os processos de mudança. Às empresas cabe desenvolver produtos e serviços inovadores, promover a interação com os centros de transferência de tecnologia da comunidade científica e guiar os processos de mudança (PEREIRA NETO; GALINDO; CRUZ, 2004).

Dessa forma, este trabalho aborda a temática envolvendo a interação universidadeempresa e o papel da universidade empreendedora no desenvolvimento tecnológico regional. Com isso, o artigo buscou identificar qual a opinião de empresários de três regiões do Rio Grande do Sul envolvidos com as instituições universitárias próximas a eles, sobre a importância do posicionamento empreendedor da universidade para o desenvolvimento regional.

Para tanto, o artigo estrutura-se em cinco partes: introdução, referencial teórico, onde aborda-se a interação universidade-empresa, descrevendo os atores envolvidos. Posteriormente descreve a interação universidade-empresa, conceitua e caracteriza o Programa Extensão Produtiva e Inovação, que é apoiado pelo Governo do Estado do Rio Grande do Sul e realizado por universidades. Na sequência aborda a metodologia e a análise da opinião desses empresários sobre a importância da universidade para o desenvolvimento regional e as considerações finais. 


\section{REFERENCIAL TEÓRICO}

\subsection{INTERAÇÃO UNIVERSIDADE-EMPRESA}

O processo de interação universidade empresa inicia na medida em que o setor produtivo necessita de uma nova tecnologia, ou até mesmo quando o setor científico produz ou gera novos conhecimentos que possuem aplicações práticas, surgindo assim, a interação entre estes setores para a promoção da inovação tecnológica (CUNHA; FISCHMANN, 2003).

A interação dos dois atores do processo se tornou primordial para a saúde econômica de um país. E para que a interação ocorra, o sistema produtivo necessita estar capacitado tecnologicamente, isso inclui uma parceria e cooperação do governo para com as empresas e universidades (MOTA, 1999).

Para que a inovação tecnológica aconteça está sendo necessário um conhecimento científico mais denso e com isso a interação entre universidade-empresa é uma das alternativas mais confiáveis. Com a interação se torna possível a união do conhecimento gerado na universidade com a prática e experiência mercadológica das organizações, uma parceria que pode modernizar o parque industrial do país (CUNHA; FISCHMANN, 2003).

De acordo com Ripper Filho (1994), interações formais exigem muito esforço de cada uma das partes para que possa dar certo, visto que cada uma possui suas prioridades e investimentos. Dessa forma, a relação só será interessante para as partes se gerarem vantagens muito maiores que seus esforços. Por exemplo: para a universidade deve haver a compreensão de que a interação contribui para a formação dos profissionais, objetivo maior dessa instituição. E a empresa ou organização, por sua vez, objetiva lucros e com isso precisa perceber diretamente essa contribuição (RIPPER FILHO, 1994).

Segundo o autor acima, o processo de interação ou parceria entre universidades e empresas possui algumas fases, denominadas de: diálogo, convivência e confiança. O diálogo pode nascer de um encontro e conferências, congressos, feiras, etc. e assim ocorrem os primeiros passos para a sequência das fases. Para um empresário é difícil compreender quando o seu problema necessita de uma nova tecnologia, ou da assimilação de uma tecnologia importada ou até mesmo de uma tecnologia conhecida pelos pesquisadores, mas desconhecida no mercado. Por este motivo a presença da universidade pode representar a solução que se espera no mercado (RIPPER FILHO, 1994). 


\section{UNIVERSIDADE EMPREENDEDORA: A ÓTICA DOS EMPRESÁRIOS SOBRE O POSICIONAMENTO EMPREENDEDOR DA UNIVERSIDADE NA CONTRIBUIÇÃO PARA O DESENVOLVIMENTO REGIONAL \\ DOI: http://dx.doi.org/10.5007/1983-4535.2015v8n4p57}

Conforme Carayol (2003) existem cinco tipos de interação universidade-empresa, são elas: a) A colaboração possui um baixo nível de risco, serviços e inovação e contratos de pesquisa. Mas possui um alto grau de pesquisa aplicada e criação de spin-offs; b) No caso da colaboração estratégica bilateral, possuem baixo risco e baixo nível de inovação, há forte presença de financiamentos públicos e grandes possibilidades de transferência de tecnologia, e para que isso tudo ocorra os parceiros devem possuir um trabalho em conjunto; c) $\mathrm{O}$ objetivo principal é a cooperação e o aumento da excelência científica. Dessa forma existem riscos e a pesquisa básica deve contemplar a inovação; d) Suas principais características são o alto risco, pesquisa básica orientada e baixo orçamento; e) São formados por grupos de consórcio associados com laboratórios de pesquisa e empresas de nível nacional. Em todos os tipos de interação citados, a universidade deve possuir um caráter empreendedor para que a interação possa ocorrer.

Segundo Etzkowitz (2009), a universidade deve assumir uma postura mais empreendedora, buscando encontrar pesquisas realizadas dentro do contexto da academia que podem servir como potenciais tecnológicos e serem colocados em prática, tornando-se assim, uma inovação. Que tem como premissa básica o crescimento econômico, onde as ondas de mudanças tecnológicas são descontínuas, destroem as velhas indústrias e geram novas SCHUMPETER (1942).

Essa postura empreendedora que a universidade deve possuir pode ser percebida quando ela se envolve com educação empreendedora, com a transferência de tecnologia e com a formação de novas empresas pelo processo de incubação. Essa cultura empreendedora poderá atuar como incentivadora para o corpo docente de uma universidade, que tradicionalmente possui foco intelectual para suas pesquisas, passando a criar um olhar voltado para um novo potencial, o mercadológico (ETZKOWITZ, 2009).

Com essa postura inovadora a universidade passa a perceber que necessita de agentes que atuem na relação entre o empresário e as intenções da universidade durante a parceria efetuada. Desse tipo de intervenção surgiram os escritórios de transferência de tecnologia, justamente para que neste setor possam estar profissionais preparados para realizar e efetivar a interação (CUNHA; FISCHMANN, 2003). 


\subsubsection{Universidade}

Discute-se o real papel da universidade, após formar profissionais, para com a sociedade e o desenvolvimento econômico e social de uma região ou país. Para analisar isso são necessários alguns indicadores como, por exemplo, integração a projetos de pesquisas inovadoras, participação em startups modernas e de tecnologias avançadas e participação em empresas competitivas (FAVA-DE-MORAES, 2000).

Para Etzkowitz (2009), a nova missão da universidade é a de capitalização do conhecimento, conectando-se aos criadores e usuários do conhecimento para estabelecer-se como um ator por mérito, ou seja, é preciso produzir e fornecer desenvolvimento econômico para que possa ser reconhecida pela sociedade.

Um importante estudo coordenado e patrocinado pelo Banco de Boston, nos Estados Unidos no ano 2000 procurou identificar qual o nível de importância do (MIT) Massachusetts Institute of Tecnolgy através da produção dos seus alunos em pesquisas inovadoras que poderiam afetar a economia local, no estado e até mesmo no exterior. A pesquisa constatou que sozinhas as empresas criadas por alunos e pesquisadores do MIT constituem a $24^{\mathrm{a}}$ economia mundial. Isso significa, mais de 1 milhão de empregos gerados por cerca de 4 mil empresas com faturamento anual de mais de US\$ 230 bilhões. Todas elas são empresas de alto nível tecnológico e inovador (FAVA-DE-MORAES, 2000).

Nesse sentido, é preciso ter atenção com a qualidade do corpo docente de uma universidade, pois essa qualidade está positivamente relacionada com o envolvimento da academia no patenteamento, na capacidade empreendedora da universidade e de seus acadêmicos, dessa forma, os professores que possuem maior envolvimento empreendedor são aqueles que irão transmitir essa capacidade e motivação em sala de aula, formando assim jovens comprometidos com o desenvolvimento econômico de um país (PERKMANN; KING; PAVELIN, 2011).

Nem todas as universidades possuem um viés empreendedor, e seu foco não é na comercialização do conhecimento e inovações geradas por seus docentes e discentes e sim o ensino, mas há uma forte corrente mundial popularizando e transformando as instituições em universidades empreendedoras, deixando de ser aquelas universidades da Idade Média, consideradas comunidades isoladas de eruditos (ETZKOWITZ, 2009). 


\subsubsection{Projeto Extensão Produtiva e Inovação (PEPI)}

O Projeto Extensão Produtiva e Inovação é uma das ações do Governo Estadual do Rio Grande do Sul, Brasil, em parceria com universidades. O Projeto busca incentivar e promover o desenvolvimento do setor produtivo em todas as regiões do Estado (MÜCKE, 2014).

O objetivo principal do projeto é proporcionar capacitação, melhoria na eficiência e eficácia produtiva em empresas de diversos ramos de atividade. Fomentar a busca permanente de inovação, sustentabilidade e orientar as empresas ao planejamento apoiando na formulação de projetos de captação de recursos financeiros para a melhoria e modernização e até mesmo à inovação (MÜCKE, 2014).

O PEPI compreende que as empresas eficientes possuem melhor resultado econômico e social, não somente por fatores internos a elas, mas também por meio da competência das instituições e até mesmo da população local que é formadora de fatores econômicos através da cultura, serviços, conhecimento e capacidade de gerar novos conhecimentos. Essas empresas podem ser geradoras de desenvolvimento local e regional, na medida em que, se apropriam destes ganhos (MÜCKE, 2014).

O projeto completa três anos de atuação no Estado do Rio Grande do Sul, no ano de 2014. Conta atualmente com 20 núcleos de extensão produtiva e inovação (NEPI), constituídos em parceria com instituições de ensino e centros tecnológicos. Cada um destes núcleos é composto por profissionais chamados de extensionistas, das mais diversas áreas de atuação: administração, engenharias, contábeis, comércio exterior, entre outros dependendo do setor da economia ao qual o atendimento se destina (MÜCKE, 2014).

Os extensionistas atuam como consultores. Auxiliam a empresa na resolução de problemas e na implementação de melhorias (MÜCKE, 2014).

As empresas que participam do projeto são empresas de pequeno e médio porte, classificadas de acordo com seu faturamento anual. Que sejam atuantes nos setores estratégicos da Política Industrial do Estado, ou até mesmo em setores que sejam priorizados pelos Conselhos Regionais de Desenvolvimento (Coredes) (MÜCKE, 2014). 


\subsubsection{Empresa}

A transição de empresas industriais para empresas do conhecimento ocorre desde o século XIX, porém as ideias e os objetivos vêm se alterando. A partir do momento em que o conhecimento faz parte da produção e comercialização de bens, produtos e serviços, as organizações objetivam cultivar parcerias e convênios com outras áreas (ETZKOWITZ, 2009).

Essas organizações são vistas como um negócio, em que vendendo um produto se obtém a receita, até que cheguem ao sucesso ou ao fracasso. Mas para as empresas que possuem interação com universidades ou institutos de pesquisa, isso pode se alterar, visto que essas organizações são baseadas na inovação organizacional e tecnológica que podem ocorrer em esferas municipais, estaduais e até mesmo internacionais, com a colaboração do governo e de institutos de pesquisa avançada (ETZKOWITZ, 2009).

As empresas tendem a criar parcerias com outras similares ao seu ramo. Na sequência com empresas maiores como, por exemplo, startups e centros de pesquisa ou universidades. Atualmente as grandes empresas transferiram unidades para os chamados parques tecnológicos ou parques científicos, instalados dentro das universidades e centros de pesquisa, para assim efetivar convênios, estar próximo ao conhecimento gerado pela pesquisa básica e aplicada, desenvolvida em grupos de pesquisa acadêmica, visando o licenciamento de novos produtos com potencial mercadológico (ETZKOWITZ, 2009).

Para Abdala; Calvosa; Batista (2009), a iniciativa privada deve ter como responsabilidade desenvolver produtos e serviços inovadores; promover a interação com a comunidade científica e liderar processos de mudança. Porém são visíveis as limitações presentes, como por exemplo, pouca capacidade de investimento para o desenvolvimento de novas tecnologias, e o despreparo acadêmico e tecnológico para a condução de pesquisas.

\subsection{DESENVOLVIMENTO REGIONAL}

As teorias clássicas a respeito do desenvolvimento regional (Teoria da Base de Exportação, a Teoria da Difusão e a Teoria do Polo de Crescimento) valorizam uma força motriz de caráter exógeno a se instalar na região para estimular o processo de desenvolvimento, a partir do paradigma "centro-abaixo" (NORTH,1990). 


\section{UNIVERSIDADE EMPREENDEDORA: A ÓTICA DOS EMPRESÁRIOS SOBRE O POSICIONAMENTO \\ EMPREENDEDOR DA UNIVERSIDADE NA CONTRIBUIÇÃO PARA O DESENVOLVIMENTO \\ REGIONAL \\ DOI: http://dx.doi.org/10.5007/1983-4535.2015v8n4p57}

Segundo North (1990) uma das principais criticas a essas teorias que servem de suporte às políticas econômicas, é a exclusão de setores fundamentais da sociedade local, isto é, a sociedade civil. Este paradigma supervaloriza as técnicas em detrimento dos anseios locais, tratando-os como meros receptores de conhecimento.

A universidade-empreendedora atuando como intermediária das ações exógenas e endógenas pode, por meio da colaboração na organização da sociedade civil e também como parte desta, transformar um impulso externo de crescimento econômico em desenvolvimento para a região (PAIVA, 2004).

Na concepção de Lima Andrade (1997) o Estado estabelece as regras do jogo, e a região é a parte negociadora que transaciona, gere conflitos e transforma o impulso externo de crescimento econômico em desenvolvimento com inclusão social. Dessa forma, a região deixa de ser vista sob o aspecto puramente geográfico e adquire feições de ator social (STHOR; TAYLOR, 1981; BOISIER, 1989; OLIVEIRA, 2002; LIMA; OLIVEIRA, 2003; BLAKELY; LEIGH, 2010).

Nessa perspectiva, o desenvolvimento regional está diretamente ligado à participação das sociedades e fortalecimento das instituições locais já que são os elementos transformadores que buscarão as soluções para as demandas da região, visando a melhoria na qualidade de vida de toda aquela comunidade. Em outras palavras, é a capacidade da própria região, a partir do estímulo externo, criar elementos (políticos, institucionais e sociais) capazes de direcionar o seu crescimento visando o desenvolvimento (OLIVEIRA; OLIVEIRA LIMA, 2003).

O desenvolvimento pode ser analisado sob diversos aspectos - econômicos, políticos, sociais, ambientais, entre outros, como sendo um processo de busca de crescimento e melhoria da vida das pessoas. A atuação da universidade nas empresas locais como instrumento de apoio por meio de consultorias gerenciais, tecnológicas, financeiras, entre outras, para as empresas locais não apenas produz desenvolvimento econômico, mas expandese ao desenvolvimento de outras ordens como reflexo desse empreendedorismo (NORTH, 1990; DIMAGGIO, 1990; BLAKELY; LEIGH, 2010; HUANG, 2011).

Para Sthor e Taylor (1981) o desenvolvimento pensado sob o paradigma "desde baixo" tem como premissa o desenvolvimento integral das habilidades e potencialidades humanas da sociedade local. 


\section{UNIVERSIDADE EMPREENDEDORA: A ÓTICA DOS EMPRESÁRIOS SOBRE O POSICIONAMENTO EMPREENDEDOR DA UNIVERSIDADE NA CONTRIBUIÇÃO PARA O DESENVOLVIMENTO REGIONAL \\ DOI: http://dx.doi.org/10.5007/1983-4535.2015v8n4p57}

Oliveira e Oliveira Lima (2003) citam Lima Andrade para conferir ao desenvolvimento "desde baixo" a necessidade de uma construção calcada em

[...] critérios alternativos de destinação de fatores, substituindo o princípio de máxima rentabilidade, pelo de mobilização integral de recursos; critérios alternativos de intercâmbio de produtos, substituindo o princípio predominante de vantagens comparativas, pelo de benefícios obtidos pelo comércio; formas específicas de organização social e econômica (desenvolvimento rural e de aldeias, uso de tecnologias intensivas em mão-de-obra através de projetos pequenos e medianos) com destaque para a organização territorial e; uma mudança no conceito de desenvolvimento, que abranja metas sociais mais amplas com uma motivação endógena (LIMA ANDRADE,1997, p.19-20)

Nesse contexto, a proposta de Boisier (1989, p.616) citado em Oliveira e Oliveira Lima (2003) é a complementação das teorias atuais de desenvolvimento econômico, cujo foco são os fatores exógenos, por meio da compreensão da importância dos fatores endógenos, isto é, saber "como" e também o "por que" do desenvolvimento. Para esse autor, o crescimento econômico regional é essencialmente originado em fatores exógenos, mas não exclusivamente. De maneira que, “[...] o processo de desenvolvimento regional deve ser considerado, principalmente, como a internalização do crescimento e, em consequência, como de natureza essencialmente endógena".

Assim, o desenvolvimento de uma região é o resultado da interação de três forças de interdependência recíproca: 1) alocação de recursos; 2) política econômica e 3) ativação social. As duas primeiras são eminentemente exógenas e centralizadas, pois, dependem de decisões provindas do Estado e a última, endógena “está associada a capacidade regional para reter e reinvestir o excedente gerado pelo processo de crescimento; a uma permanente e crescente melhora social (qualidade de vida), e à preservação no meio ambiente" (NORTH, 1990; DIMAGGIO, 1990; OLIVEIRA; OLIVEIRA LIMA, 2003, BLAKELY; LEIGH, 2010; HUANG, 2011).

Nesse contexto, a universidade-empreendedora tem a missão de fomentar $o$ desenvolvimento regional a partir de uma perspectiva endógena, ou seja, utiliza-se de fatores internos da região (não apenas econômicos, mas também com o aporte em políticas de desenvolvimento socioculturais), projetando-a para o crescimento econômico externo e ao mesmo tempo de toda a comunidade (NORTH, 1990; BLAKELY; LEIGH, 2010, HUANG, 2011). 


\section{METODOLOGIA}

Tendo em vista o objetivo deste estudo foi empregada uma pesquisa exploratória de natureza qualitativa. A estratégia de pesquisa foi o estudo de caso e como técnica de coleta de dados, fez-se uso da aplicação de um questionário com respostas abertas (KING; HORROCKS, 2010; GIBBS, 2008).

Com relação aos estudos de caso, os mesmos surgem do desejo de se compreender fenômenos sociais complexos, permitindo uma investigação para se preservar as características holísticas e significativas dos eventos da vida real (YIN, 2010). Nesse sentido, o estudo de caso se enquadra como a estratégia de pesquisa apropriada aos propósitos deste estudo. Em termos de procedimentos, a pesquisa foi desenvolvida pelas etapas apresentadas na Figura 1.

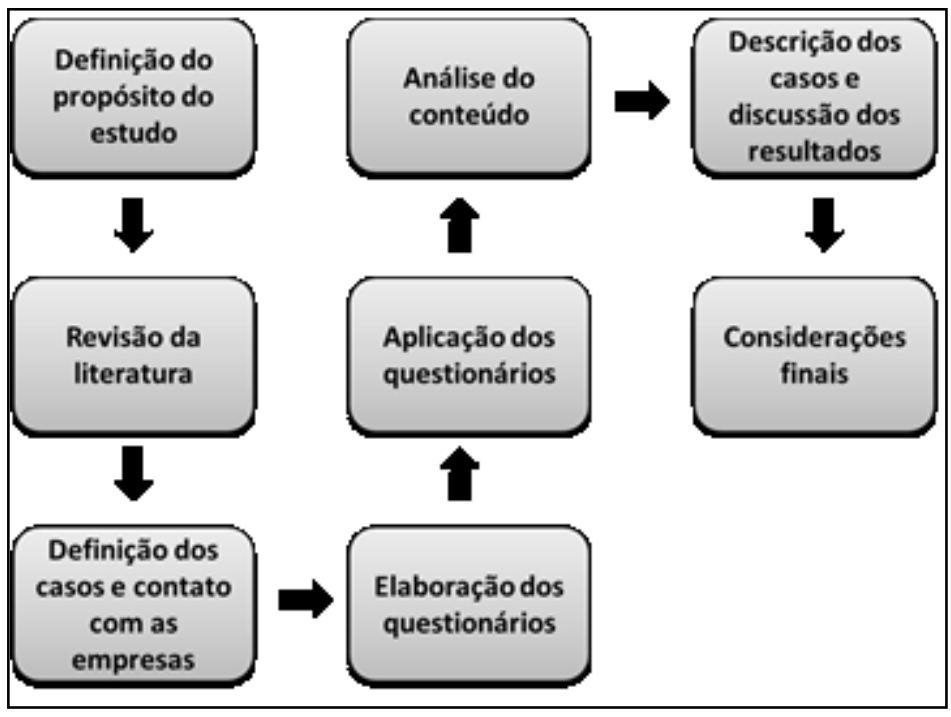

Figura 1 Procedimentos da pesquisa

Fonte: Elaborada pelas autoras (2014).

Dessa forma o escopo da presente pesquisa qualitativa compreendeu três empresas indicadas pelos coordenadores de cada núcleo, em cada uma das três regiões de atendimento do PEPI, são elas: Região da Produção, Serra e Metropolitana do Estado do Rio Grande do Sul, Brasil. Essas três regiões contam com a atuação de uma universidade conveniada ao programa do governo. O questionário para ser respondido demandou um tempo de duração de aproximadamente 15 minutos para preenchimento, dependendo de cada empresa participante. Os núcleos participantes estão denominados no texto como núcleo Produção, Serra e Metropolitano. 


\section{UNIVERSIDADE EMPREENDEDORA: A ÓTICA DOS EMPRESÁRIOS SOBRE O POSICIONAMENTO \\ EMPREENDEDOR DA UNIVERSIDADE NA CONTRIBUIÇÃO PARA O DESENVOLVIMENTO \\ REGIONAL \\ DOI: http://dx.doi.org/10.5007/1983-4535.2015v8n4p57}

$\mathrm{Na}$ etapa da coleta de dados, optou-se por realizar a aplicação de questionários de respostas abertas com os dirigentes destas empresas. A entrevista através de aplicação de questionário configura uma importante fonte de informação para o estudo de caso, permitindo questionar aos respondentes sobre os fatos de um assunto, e também as opiniões deles sobre os eventos (YIN, 2010). Nesse sentido, a entrevista através da aplicação de questionários foi considerada a forma de coleta mais apropriada para este estudo. O questionário foi elaborado a partir do referencial teórico base desta pesquisa.

O conteúdo foi analisado com base nas categorias de análise (perdas, causas e consequências) para que fosse possível identificar a opinião sobre a importância do posicionamento empreendedor da universidade para o desenvolvimento regional (BARDIN, 2010).

Na sequencia serão apresentados os núcleos do Projeto Extensão produtiva e inovação, utilizados como fonte para a realização da coleta dos dados.

\subsection{NÚCLEO PRODUÇÃO}

O núcleo Produção foi criado no ano de 2013 tem como função primordial apoiar as empresas no planejamento para investimentos de expansão e inovação; Aumentar a eficiência das empresas por meio do assessoramento direto e gratuito, visando à solução de problemas e o estabelecimento de melhorias nos aspectos da gestão, planejamento, custos, processo, produto e inovação; Proporcionar que as empresas busquem maior apoio junto a instituições ofertantes de serviços produtivos a empresas.

O núcleo está sediado no Nit (Núcleo de Inovação e Transferência de Tecnologia) da universidade conveniada com o governo. A universidade possui mais de 300 projetos de pesquisa, mais de 50 cursos de graduação e mais de 30 pós-graduação (lato sensu), 10 Mestrados e 4 programas de Doutorado. Além disso, está localizada em uma região vocacionada para a produção industrial, e que demanda inovações tecnológicas que agreguem valor e permitam ganhos de mercado. Aproximar quem gera conhecimento (academia) de quem produz bens (empresas) é fundamental para esse processo.

O núcleo atua hoje com uma equipe multidisciplinar de extensionistas nas áreas de produção do vestuário, gestão da produção, gestão empresarial, gestão financeira, gestão ambiental e saúde ocupacional. Pertencem ainda a este grupo, um coordenador, um assessor administrativo e um estagiário, totalizando 10 pessoas. 


\subsection{NÚCLEO SERRA}

O Projeto Extensão Produtiva e Inovação é desenvolvido pelo Núcleo de Extensão Produtiva e Inovação da Serra (Nepi) e concentra-se nos setores de Moda, Metal- mecânico Automotivo, Moveleiro, Automação e Controle, Máquinas e Equipamentos e Tecnologia da Informação, com o objetivo de orientar as empresas instaladas nos municípios do Conselho Regional de Desenvolvimento da Serra (Corede Serra), quanto ao seu planejamento, formulação de projetos para expansão, modernização e inovação.

A universidade conveniada possui 85 cursos de graduação, 95 habilitações, 13 programas de pós-graduação stricto sensu com 13 mestrados e 4 doutorados, 70 cursos de especialização, 800 laboratórios para todas áreas de ensino, 17 núcleos de inovação e desenvolvimento e 58 Registros de patentes no Instituto Nacional de Propriedade Intelectual INPI. O Núcleo Serra está integrado ao Escritório de Transferência e Tecnologia (ETT) da universidade participante do projeto. Criado em 1998, o ETT a possui a finalidade de promover e intermediar negociações entre a instituição e a comunidade onde atua em todo o processo. Atua com uma equipe multidisciplinar para atuar nos setores atuantes no projeto.

\subsection{NÚCLEO METROPOLITANO}

Foi lançado oficialmente no início de junho de 2014 um novo Núcleo de Extensão Produtiva e Inovação (NEPI) no Rio Grande do Sul. O novo NEPI atende empresas localizadas nas cidades de Porto Alegre, Alvorada, Viamão, Guaíba. A meta do projeto é atender 140 empresas, por meio de sete extensionistas - que atuam como consultores. O programa objetiva o aumento da eficiência e da competitividade das empresas, além do aumento da produção, do emprego e da renda, com foco na melhoria dos métodos de gestão e na busca pela inovação.

A partir de visitas dos extensionistas - que são, em sua maioria, alunos de mestrado ou doutorado da Escola de Negócios da universidade conveniada - são montados diagnósticos e planos de ação para a empresa.

O Ciclo da Inovação proposto visa promover a cultura da inovação, tornando empresas mais competitivas e agregando valor a seus negócios, por meio de capacitação, diagnóstico e assessoria empresarial na gestão da inovação. 


\section{ANÁLISE DOS DADOS}

Ao serem questionados sobre a existência de diferenças entre a universidade empreendedora e a tradicional, os empresários foram unanimes na resposta. Todos acreditam haver diferença significativa, onde destaca-se a visão do empresário do núcleo de produção que comenta sobre "o papel da universidade deve ir além da formação técnica, onde o novo formato pode ser o diferencial. Ser a inserção da universidade na comunidade onde atua, na formação técnica, social e no empreendedorismo." Para o empresário do núcleo da serra a universidade empreendedora deve desenvolver habilidades voltadas para aparte técnica e com o perfil voltado para o relacionamento pessoal, capacidade de trabalhar em equipes e ter a iniciativa e tomar decisões. Para o empresário da região metropolitana a universidade empreendedora "promove o estreitamento das relações entre o corpo docente e as empresas ativas no mercado" e também "focar na inovação" esta é a visão do empresário do núcleo da serra.

Ao que se refere às formas de interações entre as empresas e as universidades os empresários divergem quanto às ações mais globais ou pontuais. Para os empresários do núcleo serra a interação ocorre em ações mais pontuais como melhoria da produtividade, aperfeiçoamento nos produtos, como também o aproveitamento de alunos em estágios curriculares nas empresas participantes do projeto. Contudo, para os empresários dos núcleos produção e metropolitano a interação empresa e universidade pode ocorrer em diversas áreas e maneiras. De forma mais global em forma de projetos e também como afirma o empresário do núcleo produção "a interação com a universidade facilita o acesso às tecnologias e equipamentos que seria mais difícil e caro do que um acesso direto da empresa”.

Quanto as ações realizadas pelos extensionistas do projeto extensão produtiva e inovação, os empresário foram questionados se houve melhorias com as ações implementadas. Neste quesito denota-se oposição nas respostas, pois, enquanto o núcleo metropolitano encontra-se na faze de pesquisa e elaboração das ações a serem implantadas, o núcleo produção destaca que o "projeto conseguiu identificar claramente os pontos a serem melhorados na empresa, e alguns pontos a serem destacados para o futuro" porém ocorreu um déficit no projeto quanto as ações, como alega o empresário "um plano de ação e acompanhamento falta ao projeto. Pois, pensando que na maioria dos casos não existe um profissional dentro da empresa, estas ações não serão tomadas, e a longo prazo, as ideias 
geradas pelo projeto para a empresa poderão se tornar esquecidas.” Quanto ao núcleo serra, os empresários evidenciam positivamente as melhorias, mesmo que sendo através de ações simples, focadas ou até “ novas estratégias na novas estratégias na área de marketing e vendas, e melhorias no processo de produção e layout da fábrica, diminuindo perdas e com ganho na produtividade."

No que tange a atuação e a participação dos extensionistas no projeto extensão produtiva e inovação, percebeu-se o contato em todos os núcleos e há interação de várias maneiras (visitas, palestras, troca de informações).

De acordo com o empresário da região da produção, a interação com a universidade acontece de forma natural, principalmente porque tanto universidade como empresa, querem esta aproximação. Neste caso, empresa e universidade realizam a chamada pesquisa colaborativa, que visa desenvolver uma pesquisa aplicada para a geração de novas tecnologias, ou seja, o contato com a empresa iniciou pelo projeto, e na sequência as ações se estenderam para o núcleo de inovação e transferência de tecnologia, setor responsável pela interação dentro da universidade. Porém, de acordo com o empresário, quando é necessário realizar um convênio entre os atores, a morosidade do processo inicia, e de acordo com ele, em ambas as partes. Para os empresários das regiões da Serra e Metropolitana, a interação ainda é informal, realizada apenas pelas ações do projeto na empresa.

Quando questionados sobre a importância desta interação para a empresa, as respostas foram:

[...]"Sim, é importante para termos contato direto com centros de pesquisa aplicada. Além de recebermos conhecimento que se renova com os estudos propostos pelos extensionistas (empresário da região Metropolitana)[...]”.

[...]"Acho que para todas as empresas é importante esta interação. No aspecto tecnológico e produtivo, o setor acadêmico sempre está em contato e desenvolvendo pesquisas com novas tecnologias e processos. E uma empresa que tem acesso a isto, pode ter um ganho de mercado muito grande. Outro ponto interessante é a oferta de mão-de-obra qualificada que esta interação permite (empresário da região da Produção)[...]".

[...]"Sim. É de grande importância, pois o conhecimento acadêmico sempre é muito importante e útil. Em alguns pontos, um tanto quanto burocrático, mas sempre é útil (empresário da região da Serra)[...]".

Para os empresários entrevistados o desenvolvimento regional precisa abranger todos os setores da cadeia produtiva, pois os setores necessitam interagir e para que isso ocorra todos devem estar fortalecidos. Esse fortalecimento facilita a geração de novas tecnologias, as 
pesquisas colaborativas e por fim a geração de desenvolvimento para aquela determinada região.

Na opinião de todos os empresários entrevistados, a interação universidade empresa é um diferencial para impulsionar o desenvolvimento de uma região, principalmente o desenvolvimento tecnológico e econômico. Alguns dos elementos que essa interação pode gerar são as boas práticas de gestão, disseminação de conhecimentos técnicos gerados na academia, aliados a conhecimentos práticos da empresa. De acordo com o empresário da região da Serra, alguns empresários ainda não vislumbram essa interação, e acabam perdendo competitividade e diferencial mercadológico pela falta de disponibilidade para o atendimento que a universidade oferece.

Quando questionados sobre de que forma a universidade pode contribuir para o desenvolvimento regional, o empresário da região da produção, afirma que:

[...]"Várias regiões de grande importância em setores específicos tem por trás delas a participação de universidades e cursos que fazem com que pesquisas e profissionais contribuam para o seu fortalecimento (empresário da região da Produção)".

De acordo com o empresário da região da Serra, a universidade contribui de diversas formas, mas principalmente formando profissionais qualificados, gerando pesquisa de ponta, auxiliando na geração de novas ideias que contribuem para o desenvolvimento de diversas áreas em todas as regiões. Também pode auxiliar na inovação em processos de produção mais baratos e limpos, gerando diferenciais competitivos para as empresas e movimentando a economia daquela região, comenta o empresário da região Metropolitana.

\section{CONCLUSÃO}

Este trabalho teve por objetivo discorrer sobre a temática que envolve a interação universidade-empresa e o papel da universidade empreendedora no desenvolvimento tecnológico regional. Com isso, o artigo buscou identificar qual a opinião de empresários de três regiões do Rio Grande do Sul envolvidos com as instituições universitárias próximas a eles, sobre a importância do posicionamento empreendedor da universidade para o desenvolvimento regional.

Após a realização da coleta dos dados e das análises dos resultados obtidos, conclui-se primeiramente que o empresariado anseia que as universidades estejam comprometidas e alinhadas com as comunidades as quais estão inseridas, pois somente desta forma poderão 
desenvolver habilidades técnicas e auxiliar no desenvolvimento de competências, nas tomadas de decisão, nos relacionamentos com as equipes e no fomento a inovação (ETZKOWITZ, 2009).

De outro lado, a interação é dependente da visão e principalmente da necessidade do empresário (CUNHA; FISCHMANN, 2003), não bastando para isto ser identificado o potencial das universidades e as demandas do empresariado. Estas necessidades também demandam agilidade nos resultados, fator que distancia a pesquisa básica da aplicada evidenciando a necessidade de pesquisadores mais preparados e de maiores investimentos financeiros, tanto da universidade quanto do empresariado (FAVA-DE-MORAES, 2000).

Neste sentido pode-se perceber que os empresários entendem a importância da atuação extensionista, na medida em que esta possibilita a colaboração com baixos níveis de riscos, incentiva a criação de start-ups, a presença de financiamentos públicos e transferência de tecnologias, podendo desta forma tornar a pesquisa básica orientada para os interesses do mercado (ETZKOWITZ, 2009).

Bem como é possível destacar que, os empresários das regiões entrevistadas acreditam que a universidade que interage com as empresas tem uma boa contribuição para o desenvolvimento da região em que estão inseridas. Embora seja latente a necessidade de diminuir do gap existente entre elas, principalmente na morosidade dos processos dentro da universidade, enquanto a empresa necessita ser ágil e competitiva.

Como limitações, cita-se que a pesquisa em voga foi realizada em apenas três regiões do Estado do Rio Grande do Sul, sendo indicado para uma maior generalização dos dados obtidos aplicarem este estudo em um universo maior. Além disso, sugere-se a realização de estudos futuros que abordem os gargalos identificados neste estudo, observando principalmente os fatores responsáveis pelo distanciamento das pesquisas básicas e aplicadas e as influências que estas mudanças acarretariam no alinhamento entre as pesquisas básicas e a necessidade do empresariado.

\section{REFERENCIAS}

ABDALA, Márcio Moutinho; CALVOSA, Marcello Vinícius Dória; BATISTA, Luciene Gouveia. Hélice Tríplice no Brasil: Um ensaio teórico acerca dos benefícios da entrada da Universidade nas parcerias Estatais, 2009. Disponível em:

$<$ http://www.fsma.edu.br/cadernos/Artigos/Cadernos_3_artigo_3.pdf $>$. Acesso dia 09 de dez. 2012. 
BARDIN, Laurence. Análise de conteúdo. Lisboa: Edições 70, 2010.

BLAKELY, E.J.; LEIGH, N.G. Planning Local Economic Development: Theory and Practice, Sage,Thousand Oaks, CA, 2010.

BOISIER, S. Política econômica, organização social e desenvolvimento regional. In: HADDAD, P. R. (Org.). Economia regional: teorias e métodos de análise. Fortaleza: BNB/ETENE, 1989.

CARAYOL, Nicolas. Objectives, agreements and matching in scienceindustrycollaborations: reassembling the pieces of the puzzle. Research Policy, n.32, p.887908, 2003.

CASTRO, Biancca Scarpeline de Castro; SOUZA, Gustavo Costa de. O papel dos Núcleos de Inovação Tecnológica (Nit’s) nas Universidades brasileiras. Liinc em Revista, Rio de Janeiro: v. 8 n.1 Mar.2012.

CUNHA, Neila Viana da; FISCHMAN, Adalberto. Alternativas de ações estratégicas para promover a interação universidade-empresa através dos escritórios de transferência de tecnologia. Anales del Seminario Latinoiberoamericano de Gestión Tecnológica, Cidade do México, México, 2003.

DAGNINO, Renato. A relação universidade-empresa no Brasil e o argumento da hélice tripla. Rio de Janeiro. Revista Brasileira de Inovação, v. 2, n. 2, p.267-307, julho/dez, 2003.

DIMAGGIO, P.; ANHEIER, H. The sociology of nonprofit organizations and sectors, Annual Review of Sociology, Vol. 16 nº. 2, p. 137-59, 1990.

ETZKOWITZ, Henry. Hélice Tríplice. Universidade-Indústria-Governo: Inovação em Movimento. Porto Alegre: EDIPUCRS, 2009.

ETZKOWITZ, Henry; LEYDESDORFF, Loet. The dynamics of innovation: from National Systems and "Mode 2" to a Triple Helix of university - industry government relations, Research Policy, n. 29, p. 109-123, 2000.

ETZKOWITZ, Henry. et al. The Future of University and the University of the Future: evolution of ivory tower to entrepreneurial paradigm. Research Policy, n. 29, p. 313-330, 2000 .

FAVA-DE-MORAES, Flávio. Universidade, inovação e impacto socioeconômico. São Paulo Perspec., São Paulo, v. 14, n. 3, jul. 2000 . Disponível em $<$ http://www.scielo.br/scielo.php?script=sci_arttext\&pid=S0102$88392000000300003 \& \operatorname{lng}=$ pt\&nrm=iso $>$. Acesso dia 15 jul. 2014.

GIBBS, Graham. Analyzing qualitative data. Thousand Oaks: Sage Publications, 2008. 
HUANG, M-H.; RUST, R.T. Sustainability and consumption. Journal of the Academy of Marketing Science, vol. 39, p. 40-54, 2011.

KING, Nigel; HORROCKS, Christine. Interviews in qualitative research. Thousand Oaks: Sage Publications, 2010.

MAIS, Ilisangela; CARVALHO, Luciano Castro de; MACHADO, Denise Del Pra Netto; HOFFMANN, Micheline Gaia. Avaliação da percepção de professores da Furb sobre o conceito de inovação e o papel do Nit em uma Universidade. n. 28, julho: Revista Estudos do CEPE. 2008.

MOTA, Teresa Lenice Nogueira da Gama. Interação universidade-empresa na sociedade do conhecimento: reflexões e realidade. Brasília, v. 28, n. 1, Jan. 1999. Disponível em: $<$ http://www.scielo.br/scielo.php?script=sci_arttext\&pid=S0100$19651999000100011 \& \operatorname{lng}=\mathrm{en} \& \mathrm{nrm}=\mathrm{iso}>$. Acesso dia 14 Jan. 2013.

MÜCKE, Natanael et al.Manual Extensionista Projeto Extensão Produtiva e Inovação. São Leopoldo: [s.n.], 131 p. 2014.

NEVES, José Luis. Pesquisa qualitativa, características, usos e possibilidades. Caderno de pesquisas em administração. São Paulo. v. 1, n. 3. 1996.

NORTH, Douglas C. Instittutions, Institutional change and economic performance. New York: Cambridge University Press, 1990.

OLIVEIRA, Gilson Batista de. Uma discussão sobre o conceito de desenvolvimento. Revista da FAE, Curitiba, v.5, n.2, p.41-48, maio/ago. 2002.

OLIVEIRA, Gilson Batista de; OLIVEIRA LIMA, José Edmilson de. Elementos endógenos do desenvolvimento regional: considerações sobre o papel da sociedade local no processo de desenvolvimento sustentável. Rev. FAE, Curitiba, v.6, n.2, p.29-37, maio/dez. 2003.

ORLANDI, Eni Puccinelli. Análise de discurso: princípios \& procedimentos. 10. ed. Campinas, São Paulo: Pontes, 2012.

PAIVA, Carlos A. Como identificar e mobilizar o potencial de uma região para o desenvolvimento endógeno. Porto Alegre: Fundação de Economia e Estatística (Documento FEE $n^{\circ}$ 59). 2004. Disponível no site da FEE

emwww.fee.tche.br/sitefee/download/documentos/documentos_fee_59.pdf

PEREIRA NETO, André; GALLINDO, Fabiano; CRUZ, Santiago Reis da. O programa de apoio à pesquisa em empresas e o Rio Inovação: uma avaliação preliminar. Inteligência empresarial, Rio de Janeiro, v. 1, n. 21, p. 4-12, 2004.

PERKMANN Marcus; KING, Zella, PAVELIN Stephen, Engaging excellence? Effects of faculty quality on industry engagement across disciplines, Research Policy, n. 40, p.539-552, 2011. 
RIPPER FILHO, José Ellis. Ciência e tecnologia: para quê? como? In: MUSA, Edson Vaz etal. Ciência e tecnologia: alicerces do desenvolvimento. São Paulo: Cobram, 1994.

SCHUMPETER, Joseph Alois. Capitalism, Socialism, and Democracy. New York: Harper. 1942.

STHOR, W. B.; TAYLOR, D. R. Development from above or below? The dialetics of regional planning in development countries. New York: John Willey and Sons, 1981.

SILVA, Anielson Barbosa da; GODOI, Christiane Kleinübing; BANDEIRA-DE-MELLO, Rodrigo. Pesquisa qualidade em estudos organizacionais: paradigmas, estratégias e métodos. São Paulo: Saraiva, 2006.

YIN, Robert K. Estudo de caso: planejamento e métodos. 3. ed. Porto Alegre: Bookman, 2005. 